\title{
Effects of time and event uncertainty upon sequential information processing'
}

IRA H. BERNSTEIN, R. RANOOLPH BLAKE ${ }^{2}$, AND MICHAEL H. HUGHES ${ }^{3}$

UNIVERSITY OF TEXAS AT ARLINGTON

Two experiments were conducted to investigate the psychological refractory period (PRP), a delay induced into the second of two reaction times (RT) when the interstimulus interval (ISI) is short. In Experiment 1 , time and event uncertainty were factorially varied by providing or not providing $S$ with foreknowledge of the ISI and the order in which the two events would occur, respectively. ISIs of 0,50, 100, 200 , and $400 \mathrm{msec}$ were used. Time and event uncertainty produced independent degradation of both RTs. Also, the second RT $\left(\mathrm{RT}_{2}\right)$ was delayed at $50 \mathrm{msec}$ ISI when both time and event certainty were present. Experiment 2 attempted to replicate this latter finding using ISIs of 0,25 , 50,75 , and $100 \mathrm{msec}$. Delays in $\mathrm{RT}_{2}$ were found for the middle three values of ISI. These results were interpreted as supporting a modified single channel theory of the PRP.

The psychological refractory period (PRP) is defined by a delay induced into the second of two reaction times (RT) when the interval separating the two eliciting stimulus events (ISI) is short, typically $500 \mathrm{msec}$ or less, depending upon the specific task. Since Telford's (1931) initial investigation into the PRP, many studies have been conducted which have obtained appropriate delays. The PRP literature has recently been reviewed by Smith (1967), Bertelson(1966), and Reynolds (1964).

One theoretical interpretation of the PRP is that man is a single channel operator (Welford, 1952), i.e., processing the second of two stimulus events (S2) is contingent upon the processing of the first stimulus event $\left(S_{1}\right)$. According to the single channel position, $\mathrm{S}_{2}$ is temporarily stored during the formation of the first RT ( $\left(\mathrm{RT}_{1}\right)$ accounting for the observed degradation of the second $\mathrm{RT}\left(\mathrm{RT}_{2}\right)$. The basic equation descriptive of the single channel position for ISI $\leq$ $\mathrm{RT}_{1}$ is $\mathrm{RT}_{2}=2 \mathrm{RT}_{1}$ - ISI (Broadbent, 1958), which predicts that the PRP-induced delay extends throughout $\mathrm{RT}_{1}$.

Several findings have indicated that the basic single channel equation is insufficient to account for the data as delays have been observed for ISI $>\mathrm{RT}_{1}$. Hick (1948) has proposed one modification of single channel theory in which time for proprioceptive feedback is added to $\mathbf{R T}_{1}$ in estimating the refractory phase. Similarly, Davis (1956) has suggested that there is a central refractory phase extending beyond $\mathrm{RT}_{1}$ during which the hypothetical single channel is incapable of processing $\mathrm{S}_{2}$. In contrast, other investigators who are in general accord with a single channel conception of sequential information processing have found delays in $\mathrm{RT}_{2}$ only for ISIs shorter than $\mathbf{R T}_{1}$, implying that there is refractoriness for only a portion of the time required to form $\mathrm{RT}_{1}$
(Reynolds,1966). Also, Broadbent (1958) has proposed a "sampling interval" hypothesis in which storage of $\mathrm{S}_{2}$ occurs for a fixed time interval independently of ISI.

In addition to the various PRP single channel models, a number of alternative explanations have been proposed which do not assume that there are single channel limitations in processing inputs. Reynolds (1964) has proposed that observed delays are a result of a response conflict. In a related study (Reynolds, 1966), he found that responses which competed with $\mathrm{RT}_{2}$ were extinguished over trial blocks.4

Another alternative to single channel theory is based upon the concept of expectancy (Elithorn \& Lawrence, 1955; Adams, 1962). Traditionally, PRP studies have been conducted with randomly chosen ISIs across blocks of stimulus pairs. Hence, uncertainty existed regarding both the time at which $\mathrm{S}_{2}$ would occur and the particular $S_{2}$ that would be chosen for that trial. Uncertainty as to the time of occurrence of a RT signal can affect RT independently of any uncertainty as to which event will occur (Klemmer, 1956). As a result, expectancy theorists argue that the PRP is a function of the value of the ISI on a given trial relative to the values which could have occurred but did not. In contrast, single channel theorists argue that the absolute value of the ISI is the critical variable.

Only recently have studies been conducted in which time uncertainty has been either minimal (Adams,

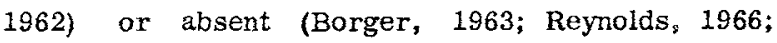
Gottsdanker \& Way, 1966). On the one hand, Adams (1962), using an event certain bisensory tracking task, and Gottsdanker and Way (1966), using a double, two choice RT task, both reported that they could not find a determinant of $\mathrm{RT}_{2}$ that was independent of time uncertainty. However, Nickerson (1965) found that the magnitude of the PRP with time uncertainty was a function of both the absolute and relative value of the ISI, suggesting that the PRP may be produced by various limitations within $S$. In their recent reviews, both Smith (1967) and Bertelson (1966) have cited additional evidence for the insufficiency of the time uncertaintyexpectancy position.

Another relevant question to the PRP is if delays in $\mathrm{RT}_{2}$ occur with both event and time certainty, i.e., when both the stimulus events and the ISI separating them are known. According to most versions of a single channel theory, storage of $S_{2}$ arises while the event uncertainty of $S_{1}$ is resolved (Creamer, 1963), a position to be denoted as the event uncertainty reduction version of single channel theory. The event uncertainty reduction model, in contrast to a more general single 
channel theory would predict, therefore, that event certain-time certain pairings should not induce a delay onto $\mathbf{R T}_{2}$. Expectancy theory would make the same prediction. However, it is also possible to conceive of time certain-event certain delays by assuming a single channel limitation on detection as well as recognition. This possibility has not been fully explored. In general, studies which have used simple RTs have used variable ISIs, and studies which have used fixed ISIs have also employed choice responses. It is, of course, difficult to conduct a time and event certain experiment adequately to meet obvious methodological objections and to control for such factors as response anticipation. However, delays in $\mathrm{RT}_{2}$ obtained under time and event certain conditions with sufficiently sophisticated Ss would be most important to the understanding of mechanisms mediating the PRP.

One relevant sequential RT study utilizing time certain-event certain pairings was conducted by Reynolds (1966). He found $\mathrm{RT}_{2}$ to be shorter than $\mathrm{RT}_{1}$ for $\mathrm{Ss}$ who had practiced at a single ISI. However, a naive $S$ population was employed which may account for the large practice effects observed throughout the experiment and failure to obtain a delay. A further difficulty in interpreting Reynolds (1966) experiment was that he reported a relatively large rise in $\mathrm{RT}_{1}$ across ISIs for Ss who were practiced at all ISIs, implying that Ss had grouped their responses. Any such response grouping would, of course, attenuate true differences between $\mathrm{RT}_{1}$ and $\mathrm{RT}_{2}$ as might be found when Ss attempted to respond independently to the two stimulus events.

Adams and Chambers (1962) used a bisensory tracking task and found that tracking latencies to visual signals which followed an auditory signal were shorter than tracking latencies to visual signals presented alone. Because of the differences between their paradigm and the unisensory RT situation, the relevance of this particular study to the present problem is somewhat limited.

In essence, both the variables affecting the PRP and the mechanisms underlying sequential information processing are in need of further exploration. Much of the theoretical discussion regarding single channel vs multi-channel theories centers around the relative contribution of two variables, time uncertainty and event uncertainty. However, the effects of these two variables are not easy to assess as comparison among prior studies is difficult in view of the many differences among PRP studies such as the use of tracking vs RT tasks, unisensory vs bisensory tasks, visual vs auditory stimulation, and naive vs sophisticated Ss.

\section{EXPERIMENT 1}

Experiment 1 was designed to examine factorially the joint effects of time and event certainty upon the PRP under conditions that allowed maximal comparability of experimental conditions as regards other experimental parameters. Time uncertainty was varied by using either a fixed ISI common to a series of stimulus pairs or a random succession of ISI. Event uncertainty was varied by informing or not informing $S$ of the order in which two stimulus events, one requiring a response with the left hand and the other with the right hand, would occur on a given trial. Thus, event uncertainty in the present situation paralleled Elithorn and Lawrence's (1955) and Marill's (1957) paradigms rather than Gottsdanker and Way's (1966) which involved sequential two-choice stimulus events. The advantage gained in the present context by varying knowledge of stimulus order to vary event uncertainty is that $\mathrm{S}_{2}$ is determined in both event certain and event uncertain conditions. Hence, direct comparison can be made among $\mathrm{RT}_{2}$ means in all conditions. Also, varying event uncertainty by varying stimulus order was deemed the most relevant procedure regarding one goal of the present study which was to try to find the minimal conditions evoking a PRP. Use of order uncertainty requires only a single decision of $S$, the order in which he is to make a pair of responses.

\section{Subjects}

\section{METHOD}

Four advanced undergraduates and one graduate psychology student, whose ages ranged from 18 to 24 , served as paid volunteers. One undergraduate and the graduate student were female. Each served for three sessions of approximately one hour's duration. Although none had prior RT experience, all had indicated a willingness to serve as trained Ss as part of the senior author's research project concerning latency mechanisms and had some course familiarity with RT findings.

\section{Apparafus and Stimuli}

Stimulus events were presented on a three-channel Scientific Prototype model GB tachistoscope. Each stimulus event consisted of the appearance of a $46^{\prime}$ visual angle spot of light to the left or right of a central fixation point of like size. The stimulus events and fixation point were produced by back illumination of an opaque black card with an appropriately sized hole, placed in the front card holders of the tachistoscope. Illumination was provided by a pair of Argon-Mercury bulbs located in each channel of the tachistoscope. The maximum width of the display was $3^{\circ} 20^{\prime}$ visual angle. The luminance of the fixation point was $11 \mathrm{ft}-\mathrm{L}$, and the luminance of the stimulus events was $16 \mathrm{ft}-\mathrm{L}$, as measured by an SEI spot photometer. Masking noise was generated by a white noise generator. Onset of the light in a stimulus event channel simultaneously started one of a pair of Hunter Klockounters through a system of Scientific Prototype dc powered electronic buffers, reed relays, and flip-flops, for each stimulus event channel. The S's response, a homolateral telegraph key depression, reset the appropriate flip-flop and stopped the Klockounter. 


\section{Procedure}

In each session, ten $\mathrm{RT}_{1}$ and $\mathrm{RT}_{2}$ responses were obtained at each of five ISIs $(0,50,100,200$, and 400 msec) in each of four conditions: time certainty + event certainty (TE), time certainty + event uncertainty $(\mathrm{Te})$, time uncertainty + event certainty (tE), and time + event uncertainty (te).

In the $\mathrm{TE}$ condition, Ss were informed by $\mathrm{E}$ of the order of the event pairs, shown the ISI for a given block of 10 trials, and then run with five 1-r pairings followed by five $r-1$ pairings (or the reverse). In the Te condition, Ss were also shown the ISI to be used on a given block of 10 trials. However, the order across a 10 trial block was random. Demonstration of the ISI in both event certain conditions was done. In both the $t E$ and te conditions, Ss were not informed of the ISI which was randomized for blocks of 50 trials. However, in the $\mathrm{tE}$ condition, $\mathrm{Ss}$ were informed of the order to be used on a given trial.

A point of note is that the $0 \mathrm{msec}$ ISI point for the TE and Te conditions was functionally equivalent since foreknowledge of the "order" of two events is irrelevant when they are simultaneous. The $0 \mathrm{msec}$ data point was included in the $\mathrm{tE}$ condition merely to preserve the orthogonality of the overall design.

Thus, 10 RT pairs were obtained in each of four condition for each session at each ISI. The $10 \mathrm{RT}_{1}$ and $\mathrm{RT}_{2}$ responses are denoted as "cells" in data analyses. Half were left-right orderings and half were the reverse. Conditions within sessions and ISIs within conditions were appropriately counterbalanced both across sessions and Ss. Forty additional warm-up pairs were run at the beginning of each session. In addition, a single block of 50 simple and 50 two-choice RTs were obtained from each $S$ during the third session.

The results of a pilot study conducted with paid volunteers recruited from a section of introductory psychology, employing the same general procedures, indicated that uninstructed and naive Ss tend to delay their first response proportional to the ISI and emit nearly synchronous (grouped) responses. To minimize the interpretive difficulties produced by grouping, Ss were carefully instructed to attempt to respond independently to the two stimulus events and further to attempt to keep $\mathrm{RT}_{1}$ at a constant level across ISIs in each condition. Grouping tendencies have made the results of various prior studies difficult to interpret (e.g., Borger, 1963; Reynolds, 1966).

Catch trials (no signal present) were not run in the present study since it was desired to keep the decisional aspects of the present situation minimal and to examine the effects of such induced choice in later research. Also, to keep anticipatory responding to $S_{1}$ at a minimum, no warning signal was employed. The effects of a warning signal were investigated separately in Experiment 2.

\section{RESULTS}

A large number of systematic sources of variation were employed in Experiment 1 (Ss, time certainty vs time uncertainty, event certainty vs event uncertainty, ISIs, $\mathrm{RT}_{1}$ vs $\mathrm{RT}_{2}$, and sessions) which rendered data analysis through a single analysis of variance impractical. Instead, two basic sets of ANOVA, each restricted to three factors, were performed. The first set compared ISIs, $\mathbf{R T}_{1}$ vs $\mathrm{RT}_{2}$, and $\mathrm{Ss}$, separately for each session by condition combination based upon cell sums. Presented in Table 1 are the $F$ ratios derived from these analyses. Included within these analyses are the separate trends for $\mathrm{RT}_{1}$ and $\mathrm{RT}_{2}$ across ISIs; i.e., the factors were examined within the context of a nested as well as a crossed ANOVA format. In order to evaluate differences across conditions that may have affected RTs, the RTs separately, the second sets of ANOVAs compared ISIs, Ss, and a pair of experimental conditions, e.g., $T E$ vs Te. The second set of analyses were conducted separately for each possible pair of conditions, session and RT; the dependent variable was again cell sums. The $F$ ratios derived from the second set of analyses are summarized in Table 2 . The $F$ ratios for ISIs have been deleted in Table 2 as the basic ISI data are contained in Table 1.

Supplementary analyses were made at selected ISIs in order to evaluate the statistical significance of differences observed at certain critical ISIs. The data for these analyses were obtained by pooling comparable data cells across the three sessions, resulting in a distribution of 30 responses per $\mathrm{S}$ for each ISI and condition combination. Two such distributions were compared on an individual $\mathrm{S}$ basis by means of a sign test. Because between- and within-sessions practice

Table 1. Values of $F$ for analyses of variance conducted for each session and condition.

\begin{tabular}{|c|c|c|c|c|c|c|}
\hline \multirow[b]{3}{*}{ Session } & \multicolumn{6}{|c|}{ Condition } \\
\hline & \multicolumn{3}{|c|}{$T E$} & \multicolumn{3}{|c|}{$\mathrm{Te}$} \\
\hline & 1 & 2 & 3 & 1 & 2 & 3 \\
\hline$|S|(A)$ & 1.46 & 2.66 & 2.54 & $9.55^{* *}$ & $10.15 * *$ & $14.11 * *$ \\
\hline $\mathrm{RT}_{1}$ vs $\mathrm{RT}_{2}(\mathrm{~B})$ & $<1$ & $6.42 *$ & $5.82 *$ & $112.10^{* *}$ & $29.70 *$ & $91.60 * *$ \\
\hline$A \times B$ & $6.53 * *$ & $9.81 * *$ & $23.51 * *$ & $15.43^{* *}$ & $11.20 * *$ & $22.96 * *$ \\
\hline IS| across RT & 1.08 & $<1$ & 2.74 & 8. $16 * *$ & 4. $11 * *$ & $11.67 * *$ \\
\hline ISI across $\mathrm{RT}_{2}$ & $5.72 * *$ & $10.30 * *$ & $16.61 * *$ & $12.81 * *$ & $17.11^{* *}$ & $22.91 * *$ \\
\hline & & & Conditi & & & \\
\hline
\end{tabular}

\begin{tabular}{|c|c|c|c|c|c|c|}
\hline \multirow[b]{2}{*}{ Session } & \multicolumn{3}{|c|}{ tE } & \multicolumn{3}{|c|}{ te } \\
\hline & 1 & 2 & 3 & 1 & 2 & 3 \\
\hline$|S|(A)$ & 4.55 & $46.68^{* *}$ & $6.72 * *$ & $12.55^{*}$ & $* 15.82 * *$ & $41.30 * *$ \\
\hline$R T_{1} v s T_{2}(B)$ & $<1$ & 3.80 & 3.38 & $28.47 *$ & $* 194.87 * *$ & $12.16 * *$ \\
\hline$A \times B$ & $13.91 * *$ & $25.76 * *$ & $28.19 * *$ & $10.53 *$ & * 19.73** & $32.57 * *$ \\
\hline $\begin{array}{l}\text { ISI across RT } \\
\text { ISI across } R T_{2}\end{array}$ & $\begin{array}{c}<1 \\
15.70^{* * *}\end{array}$ & $\begin{array}{c}2.00 \\
65.00 * *\end{array}$ & $\begin{array}{l}2.47 \\
28.17^{* *}\end{array}$ & $\begin{array}{r}<1 \\
22.41\end{array}$ & $\begin{array}{c}<1 \\
34.80 * *\end{array}$ & $\begin{array}{c}<1 \\
72.89 * *\end{array}$ \\
\hline
\end{tabular}

$* p<.05$

$* * p<.01$

df $A$ and df $A x B=4.16 ;$ df $B=1,4$; df ISI across $R T_{1}$ and ISI across $R T_{2} p=4.32$ (based upon pooled $A x S$ and $A x B x S$ error terms) Note: Computing $F$ for ISI across $R T_{1}$ in the $T e$ conditions but excluding the 0 msec point generates values $<1.00$ for all sessions. At 0 msec ISI, there is, of course, no event uncertainty. This point was included to preserve orthogonality of the overall design. 
Table 2. Summary $F$ values for conditions (cond.) and conditions ISI interaction (Int.), presented for each pair of conditions, sessions, and $R T_{1}$ and $R T_{2}$.

\begin{tabular}{|c|c|c|c|c|c|c|}
\hline \multirow[b]{2}{*}{ Analysis Effect } & \multicolumn{3}{|c|}{$\begin{array}{c}R T_{1} \\
\text { Session }\end{array}$} & \multicolumn{3}{|c|}{$\begin{array}{c}\mathrm{RT}_{2} \\
\text { Session }\end{array}$} \\
\hline & 1 & 2 & 3 & 1 & 2 & 3 \\
\hline $\begin{array}{c}\text { TE vs tE cond. } \\
\text { int. }\end{array}$ & $\begin{array}{c}26.27^{* *} \\
<1\end{array}$ & $\begin{array}{c}69.47 * * \\
3.01 *\end{array}$ & $\begin{array}{c}80.44^{*} \\
1.00\end{array}$ & $\begin{array}{c}35.78^{*} \\
2.57\end{array}$ & $\begin{array}{l}12.85^{*} \\
4.83^{* *}\end{array}$ & $\begin{array}{r}20.98^{*} \\
3.14^{*}\end{array}$ \\
\hline $\begin{array}{c}\text { TE vs Te cond. } \\
\text { Int. }\end{array}$ & $\begin{array}{l}20.11^{*} \\
6.48^{* *}\end{array}$ & $\begin{array}{l}15.46^{*} \\
5.13^{* *}\end{array}$ & $\begin{array}{l}20.27^{*} \\
7.54^{* *}\end{array}$ & $\begin{array}{l}2.60 \\
1.50\end{array}$ & $\begin{array}{l}9.25^{*} \\
6.05^{* *}\end{array}$ & $\begin{array}{c}17.24^{*} \\
1.36\end{array}$ \\
\hline $\begin{array}{c}\text { tE vs Te cond. } \\
\text { Int. }\end{array}$ & $\begin{array}{l}6.39 \\
8.22 * *\end{array}$ & $\begin{array}{c}<1 \\
5.02 * *\end{array}$ & $\begin{array}{c}<1 \\
18.02 * *\end{array}$ & $\begin{array}{l}1.50 \\
11.46^{* *}\end{array}$ & $\begin{array}{l}3.61 * \\
9.76^{*}\end{array}$ & $\begin{array}{l}13.17^{*} \\
5.63^{* *}\end{array}$ \\
\hline $\begin{array}{c}\text { Tevs te cond. } \\
\text { Int. }\end{array}$ & $\begin{array}{r}39.91 * * \\
9.26 * *\end{array}$ & $\begin{array}{r}16.37^{*} \\
3.46^{*}\end{array}$ & $\begin{array}{c}9.76^{*} \\
16.19^{* *}\end{array}$ & $\begin{array}{l}5.32 \\
11.83^{* *}\end{array}$ & $\begin{array}{r}13.19^{*} \\
4.32 *\end{array}$ & $\begin{array}{l}6.79 \\
6.73^{* *}\end{array}$ \\
\hline $\begin{array}{r}\text { tE vs te cond. } \\
\text { Int. }\end{array}$ & $\begin{array}{c}24.08 * * \\
1.49\end{array}$ & $\begin{array}{c}16.21 * \\
1.03\end{array}$ & $\begin{array}{l}3.07 \\
4.87 * *\end{array}$ & $\begin{array}{l}1.20 \\
1.35\end{array}$ & $\begin{array}{c}<1 \\
9.99 * *\end{array}$ & $\begin{array}{r}<1 \\
1.85\end{array}$ \\
\hline $\begin{array}{c}\text { TE vs te cond. } \\
\text { Int. }\end{array}$ & $\begin{array}{l}40.69 * * \\
2.31\end{array}$ & $\begin{array}{c}33.26 * * \\
1.00\end{array}$ & $\begin{array}{l}66.32 * * \\
5.05\end{array}$ & $\begin{array}{l}18.14^{* *} \\
1.61\end{array}$ & $\begin{array}{r}16.16^{* *} \\
4.78^{* *}\end{array}$ & $\begin{array}{r}22.12^{* *} \\
3.95^{* *}\end{array}$ \\
\hline
\end{tabular}

Note: The conditions effect was tested against the conditions $x$ Ss interaction (df $14 ; F p<.05=7.71$ and $F p<.01=21.20$ ). The conditions by ISI interaction was tested against the conditions of ISI by Ss interaction (df $=416: F p<.05=3.01$ and $F p<.01=$ $4.77)$.

effects commonly influenced all distributions, it was decided to treat distributions as related measures independently of whether they were $\mathrm{RT}_{1}$ vs $\mathrm{RT}_{2}$ comparisons or cross-conditions comparisons. The $Z$ scores derived from the sign tests for each $\mathrm{S}$ were then pooled and an overall $\chi^{2}$ test $(\mathrm{df}=10)$ was then performed in the supplementary analysis to eliminate the effects of skewness in RT distribution. Because the analyses reported in Tables 1 and 2 involved the sum of $10 \mathrm{RT}$ measures, parametric tests were deemed appropriate as the central limit theorem would force normality onto the distributions.

Despite an overall decrease in RT across the three sessions, the trends were relatively consistent across sessions and Ss. Hence, $\mathrm{RT}_{1}$ and $\mathrm{RT}_{2}$ were averaged, separately for each condition and ISI, across Ss and sessions. The pooled data means are presented in Fig. 1.

Two trends common to all conditions were noted. First, $\mathrm{RT}_{1}$ was longer than the simple single RT means. This delay in $\mathrm{RT}_{1}$ replicates a previous finding by Gottsdanker, Broadbent and Van Sant (1963).

The second finding, seen in Table 1 , was that $\mathbf{R T}_{\mathbf{1}}$ did not vary significantly across ISIs in any condition but Te, and, as Fig. 1 indicated, the corresponding absolute magnitudes of differences in $\mathrm{RT}_{1}$ across ISIs were small. When the $0 \mathrm{msec}$ ISI is excluded from analyses of the Te data, for the obvious reasons cited above, the $F$ ratios for ISI become nonsignificant ( $F<$ 1 for all sessions). In essence, the findings for $R T_{1}$ indicate that the task instructions minimized the tendency of Ss to group their responses. Comparisons involving $\mathbf{R T}_{2}$, to be described below, are accordingly minimally biased by changes in $\mathbf{R T}_{1}$.

Analysis of $\mathrm{Ss}$ performance in the TE conditions suggests a rise in $R_{2}$ at 50 msecs ISI followed by a monotonic decline thereufter. The pooled results of sign tests conducted at 0,50 , and 100 msec ISI confirmed a nonmonotonic relation between $\mathrm{RT}_{2}$ and ISI. At 0 msec ISI, the difference between $R T_{1}$ and $R T_{2}$ was not significant for any of the five Ss nor was the pooled data significant $\left(\chi^{2}=10.82\right)$. At $50 \mathrm{msec}$ ISI, RT 2 was significantly greater than $R_{1}\left(\chi^{2}=46.05, p<\right.$ .01). The differences were significant on an individual basis for three of five Ss beyond the .01 level and beyond the .05 level for a fourth S. Except for a slight reversal in the remaining $S$ during the second session, the delay in $\mathrm{RT}_{2}$ was relatively stable across sessions.

At 100 msec ISI, $\mathrm{RT}_{2}$ was significantly shorter than $\mathrm{RT}_{1}\left(X^{2}=24.78, \mathrm{p}<.01\right)$. The sigmificance of this difference at $100 \mathrm{msec}$ ISI is somewhat artifactual, however, as it arose solely from the performance of one $S$. The remaining four Ss showed only slight trends, two Ss actually having longer $\mathrm{RT}_{2}$ s. Conversely, however, there is no evidence that $R_{2}$ is greater than $R_{1}$ at 100 msec ISI. At the 200 and $400 \mathrm{msec}$ ISIs, $\mathrm{RT}_{2}$ was consistently shorter than $\mathrm{RT}_{1}$. Reynolds (1966) has previously noted the facilitation to a warning signal function of $S_{1}$. It appeared that there was some tendency for anticipatory $\mathrm{RT}_{2}$ responses to have been made with longer ISIs. RTs of less than $150 \mathrm{msec}$ were uncommon for $R_{1}$ at all ISIs and $R T_{2}$ for ISI of less than $200 \mathrm{msec}$, but were relatively common for $\mathrm{RT}_{2}$ at 200 and $400 \mathrm{msec}$ ISIs.

In the Te condition, the introduction of event uncertainty produced an expected increase in $\mathbf{R T}_{1}$ for all ISIs $<50$ msec. It is of interest to note in Fig. 1 that $R T_{2}$ is approximately at the same level as $R T_{1}$ at $50 \mathrm{msec}$ ISI and only slightly less than $R T_{1}$ at $100 \mathrm{msec}$. To evaluate the statistical significance of the possible failure of Ss to utilize the advance information contained in $\mathrm{S}_{1}$, sign tests were made comparing $\mathrm{RT}_{2}$ in the $\mathrm{TE}$ and $\mathrm{Te}$ conditions at 50 and 100 msec ISI. In both comparisons, $\mathbf{R T}_{2}$ was significantly longer in $\mathrm{Te}$ condition than in the TE condition $\left(X^{2}=\right.$

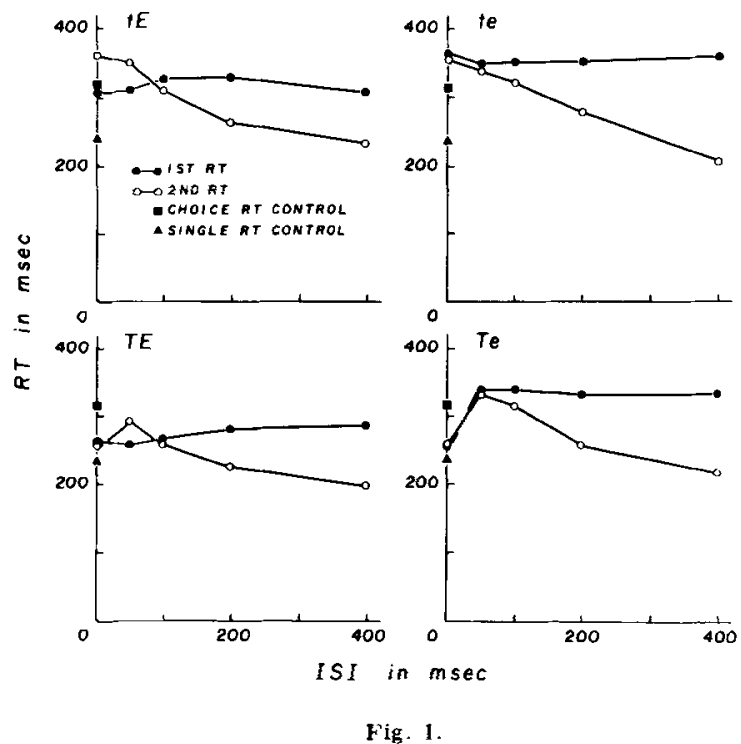

Fig. 1 . 
27.96 and 46.05 for the 50 and $100 \mathrm{msec}$ comparison, respectively, $\mathrm{p}<.01$ ).

As expected, the introduction of time uncertainty in the $\mathrm{tE}$ condition lengthened $\mathrm{RT}_{2}$ as compared to the $\mathrm{TE}$ condition. Although the effect was most prominent at shorter ISIs, the effect was noted even at longer ISIs. $\mathrm{RT}_{2}$ was longer in the $\mathrm{t} E$ condition than in the $\mathrm{TE}$ condition at both 200 and $400 \mathrm{msec}$ ISI ( $X^{2}=31.64$ and 27.47, respectively; $p<.01$ ), although the findings for the $400 \mathrm{msec}$ ISI are largely an artifact in one S. In addition, time uncertainty affected $R T_{1}$, i.e., a time uncertain event following $S_{1}$ lengthened $\mathrm{RT}_{1}$ more than a time certain event, as may be seen from Table 2. The difference in $\mathrm{RT}_{1}$ between time certain and time uncertain ISIs was, in fact, as great as the difference in $\mathrm{RT}_{1}$ between event certain and event uncertain $\mathrm{S}_{1}$ events. The partial equivalence of event and time uncertainty may be inferred from the lack of significant differences between $\mathrm{Te}$ and $\mathrm{t} E$ conditions in the $\mathrm{RT}_{1}$ analyses. Despite the difference in event uncertainty between the $\mathrm{Te}$ and $\mathrm{tE}$ conditions, differences were small and nonsignificant.

A question that arises in the te condition is the extent to which time and event uncertainty act in a cumulative manner to lengthen RT. Evidence for the cumulative effects of time and event uncertainty was found in the analysis of the $\mathrm{RT}_{1}$ data as $\mathrm{RT}_{1}$ was longer in the te condition than either the $\mathrm{tE}$ or the $\mathrm{Te}$ conditions in all three sessions. In contrast, $\mathrm{RT}_{2}$ in the te condition did not differ from the $\mathrm{tE}$ condition in any session and differed from the Te condition in only one session.

A second finding of interest in the te condition was the monotonic decline in $\mathrm{RT}_{2}$ across ISIs. Using time and event certain pairings, both Marill (1957) and Elithorn and Lawrence (1955) obtained shorter $\mathrm{RT}_{2}$ at $0 \mathrm{msec}$ than at $50 \mathrm{msec}$. It should be noted, however, that the range of ISIs in the above studies differed from the present which may, in part, account for the discrepancy.

\section{EXPERIMENT 2}

The delay in $\mathrm{RT}_{2}$ at $50 \mathrm{msec}$ ISI in the TE condition found in Experiment 1 was felt to be a finding of potential theoretical interest. This delay is difficult for expectancy and the event uncertainty version of single channel theory to account for. By definition, neither uncertainty as to the ISI, nor $\mathrm{S}_{1}$, the factors relevant to the PRP within the respective contexts of the two theories, were present. However, there were several possible sources of artifact in Experiment 1 that suggested the need for replication of the TE condition. Although the effect was observed throughout all three sessions for four of five Ss and in two of three sessions for the remaining $S$, it was decided to run Ss for a greater number of sessions to minimize the possibility of a practice artifact. Even though Ss in Experiment 1 were more sophisticated than the commonly used introductory psychology student population, none had any actual RT experience. It was also felt that blocks of 10 trials per cell may not have familiarized Ss with ISIs sufficiently. In Experiment 2, each S was run for six sessions in order to minimize the possible effects of lack of sophistication, and blocks of 30 trials at a single ISI were used in attempt to rule out the possible effects of unfamiliarity with the ISI. Another goal of Experiment 2 was to investigate the possiblilty that the delay in $\mathrm{RT}_{2}$ in the $\mathrm{TE}$ condition may have arisen from the lack of a warning signal for S. Finally, all ISI used in Experiment 2 were $\leq 100 \mathrm{msec}$ to allow more detailed examination of the relation between $R T_{1}$ and $\mathrm{RT}_{2}$ at short ISIs.

\section{METHOD}

Subjects

Five advance undergraduate psychology majors, four male and one female, served for six sessions of approximately one $h$ duration. Their ages ranged from 18-22. All were participants in the senior author's program of RT studies, and three Ss had served in Experiment 1 .

\section{Apparatus and Stimuli}

The basic apparatus was the same as that employed in Experiment 1. One minor change in circuitry was introduced, a warning signal produced by a $.1 \mathrm{sec}$ offset of the fixation field at the beginning of each trial under those conditions using a warning signal. The foreperiod delay with a warning signal present was a constant $2 \mathrm{sec}$.

\section{Procedure}

Following the warm-up trials used at the beginning of each session, a total of 300 trials were run per session. Half of these were run with a warning signal (WS) and the remainder without a warning signal (NWS). Blocks of 30 trials were run at each of five ISIs: 0 , $25,50,75$, and $100 \mathrm{msec}$ with the WS always or never present on a given block. Blocks of 15 trials within a given condition were run with a fixed 1-r or $r-1$ order followed by the reverse. The remaining procedures were the same as those employed in Experiment 1.

\section{RESULTS}

The data analysis in Experiment 2 was derived from the last four sessions. Each cell consisted of 120 first or second RTs at each S by ISI by warning signal condition combination. Presented in Fig. 2 are the $\mathrm{RT}_{1}$ and $\mathrm{RT}_{2}$ means as a function of ISI and warning signal, averaged across Ss. Except for differences in overall performance level and one other exception to be discussed below, the means represent trends common to all five Ss.

As can be seen from Fig. 2, there is evidence of a delay in $\mathrm{RT}_{2}$ at all intermediate ISIs $(25,50$, and 75 msec). The magnitude of the delay in $\mathrm{RT}_{2}$ as compared to $\mathrm{RT}_{1}$ is, in fact, somewhat larger than that observed in Experiment 1 at the comparable $50 \mathrm{msec}$ ISI, 60 


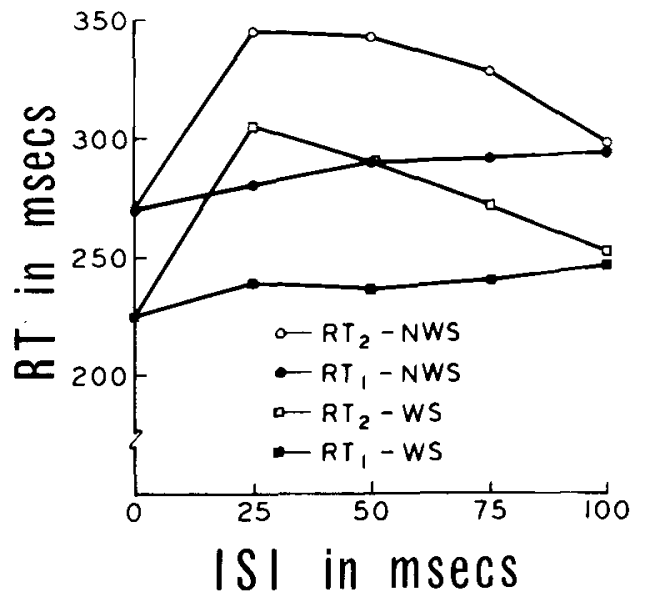

Fig. 2.

msec as opposed to the $34 \mathrm{msec}$ noted in Experiment 1. The use of a warning signal had no apparent effect other than to produce an overall $50 \mathrm{msec}$ facilitation. Both the $\mathbf{R T}_{1}$ and $\mathrm{RT}_{2}$ function in the WS condition are essentially parallel to the respective function in the NWS condition. Finally, there is a somewhat greater rise in $R_{1}$ across ISIs in the present experiment than in Experiment 1.

To evaluate the statistical significance of these apparent effects, two analyses were conducted. The first was a four-way ANOVA (Ss, ISIs, WS vs NWS, and $\mathrm{RT}_{1}$ vs $\mathrm{RT}_{2}$ ) based upon the cell sums. Three significant effects were obtained: ISI ( $F=14.10$, df $=4 / 16, p<.01$ ), WS vs NWS $(F=14.10, \mathrm{df}=1 / 4, \mathrm{p}<.05)$ and the ISI by $\mathrm{RT}_{1}$ vs $\mathrm{RT}_{2}$ interaction $(\mathrm{F}=15.48, \mathrm{df}=4 / 16, \mathrm{p}<.01)$. The main effect of $\mathrm{RT}_{1}$ vs $\mathrm{RT}_{2}$ approached a significant level $(\mathrm{F}=7.38, \mathrm{df}=1 / 4)$.

The significant effect of WS vs NWS and the lack of any significant interaction of this variable with other experimental variables confirms the above impression that the WS had only a nonselective facilitory effect on RT. In order to examine the significant ISI by $\mathrm{RT}_{1}$ vs $\mathrm{RT}_{2}$ interaction in detail, a trend analysis was made separately for the $\mathrm{RT}_{1}$ and $\mathrm{RT}_{2}$ means across ISIs, pooling across the WS vs NWS dimension. This analysis confirmed the apparent rise in $\mathrm{RT}_{1}$ with ISI. Although the overall effect of ISI was not significant for $R T_{1}$ $(F=2.66$, $d f=4 / 16)$, the linear component was highly significant $(F=9.51$. $d f=1 / 16, p<.01)$ and accounted for $90 \%$ of the overall variation of $\mathrm{RT}_{1}$ across ISIs. For $\mathrm{RT}_{2}$, the overall effect of ISI was highly significant ( $F=34.27$, df $=4 / 16, p<.01$ ), as was the quadratic component of this trend $(F=120.69, \mathrm{df}=1 / 16, \mathrm{p}<.01)$ which accounted for $80 \%$ of the variation in $\mathrm{RT}_{2}$ across ISIs. The linear component of the trend was not significant $(F=3.01, \mathrm{df}=1 / 16)$.

An attempt was made to ascertain why there was a more pronounced grouping effect (rise in $\mathrm{RT}_{1}$ with ISI) observed in the present experiment. In part, this seemed due to fatigue or boredom effects, as there was a tendency for the rise in $\mathrm{RT}_{1}$ to become accen- tuated in later sessions. It also seems possible that the different range of ISIs may have produced different contextual effects despite the time certainty. The collective results of both experiments would also suggest that the delay in $\mathrm{RT}_{\mathbf{2}}$ with time and event certainty is also subject to session-to-session variation, decreasing slightly and then increasing, which would explain why the absolute magnitude of the effect was larger in the present experiment. In general, however, the variation was relatively slight and the delay did not disappear at any stage of practice.

The second analysis on the present data consisted of sign tests comparing $\mathrm{RT}_{1}$ and $\mathrm{RT}_{2}$ at each ISI, separately for the WS and NWS conditions and using the same pooling technique as employed in Experiment 1 . At $0 \mathrm{msec}$ ISI, there was no difference between $\mathrm{RT}_{1}$ and $\mathrm{RT}_{2}\left(\chi^{2}=10.42\right.$ and 15.69 , respectively, for the NWS and WS conditions). At all intermediate ISIs, all values of $x^{2}$ were significantly well beyond the .0001 level; a fact generally true of the individual $z$ scores. The lowest $z$ score for an individual $S$ was 2.38 at $75 \mathrm{msec}$ ISI and at the 25 and 50 msec ISIs, more than $95 \%$ of the $\mathrm{RT}_{2}$ responses were longer than $\mathrm{RT}_{1}$. At $100 \mathrm{msec}$ there was evidence of idiosyncratic performance not noted at shorter ISIs; one $\mathrm{S}$ had longer $\mathrm{RT}_{1}$ responses on almost all trials, whereas a second $\mathrm{S}$ showed the reverse pattern. There was little difference between $\mathrm{RT}_{1}$ and $\mathrm{RT}_{2}$, in general, for the remaining Ss.

\section{DISCUSSION}

Basically, the following RT delays produced by the sequential nature of the PRP task were observed in Experiment 1: (a) an overall increase in $\mathrm{RT}_{1}$ in all conditions as compared to single simple RTs, (b) an increase in $\mathrm{RT}_{2}$ at $50 \mathrm{msec}$ in the $\mathrm{TE}$ condition, (c) an increase in both RTs induced by time uncertainty, (d) an increase in $\mathrm{RT}_{2}$ at short ISIs induced by event uncertainty. Although both time and event uncertainty separately affected $\mathrm{RT}_{1}$, no such cumulative effects were found for $\mathrm{RT}_{2}$. Experiment 2 further indicated that the delay in $\mathbf{R T}_{2}$ with time and event certainty held for fairly well practiced Ss and was nonmonotonically related to ISI for ISIs of 0 to $100 \mathrm{msec}$.

Two of the above findings are of special relevance to the issues, as to whether man is a single channel operator or, conversely, whether the effects of time uncertainty and consequent expectancy effects produce artifactual single channel limitations in a system that is inherently multichannel. These findings are the delay present with time and event certainty, which will be denoted as the TE delay, and the additional delay imposed onto $\mathrm{RT}_{2}$ occurring with event uncertainty. Although both of these findings are in need of further investigation, it would seem justified at present to assume that an expectancy theory cannot adequately account for these two delays; thus, both findings support the conclusions reached by Smith (1967) and Bertelson (1966) that the PRP is a consequence of single channel delays. However, it should be noted also that 
factors which delay $\mathrm{RT}_{1}$, some of which were previously noted by Gottsdanker, Broadbent, and Van Sant (1963), are difficult for single channel theories to account for. These theories are concerned with sources of the proactive effects of $S_{1}$ upon $S_{2}$ and not the converse. The degrading effects of time uncertainty upon $\mathrm{RT}_{1}$, for example, is a retroactive effect. Although the following discussion is oriented towards a single channel position, it seems reasonable to assume additional degrading factors that do not involve single channel limitations.

The locus of the TE delay is a question of particular interest for further research. The present study would suggest that it cannot be accounted for strictly in terms of peripheral factors. On the response side, different motor systems were employed, minimizing any peripherally based response conflict. On the stimulus side, it would appear difficult to see how such factors as inhibitory masking or luminance summation would be of relevance. First, masking has relatively little, if any effect, upon simple RT (Fehrer \& Raab, 1962). Also, luminance summation should have facilitated $\mathrm{RT}_{2}$ if its effects were simply proactive or have had no differential effect if it were to exert symmetrical influences. Basically, the ISIs used were beyond the temporal limits in which the critical aspects of the RT signal itself are modifiable at a peripheral level.

Previous research dealing with central components of latency mechanisms suggests at least three points at which delays may occur. One site is the filter proposed by Broadbent (1958). He has argued for a filter mechanism which is capable of selecting stimuli on the basis of simple physical parameters, such as physical location, which either admits stimuli to a central processing system or temporarily gates their entry. In the PRP situation, the filter mechanism is utilized by assuming that inputs are sampled from different channels for a fixed period of time switching rate of 3 cps (the "sampling interval" hypothesis), a figure suggested from several ines of research. The delay in switching attention from Channel 1 to Channel 2 would account in principle for the observed delays with time and event uncertainty. However, the 3 cps rate is too slow to account for the fact that the delays were found only for ISIs less than $100 \mathrm{msec}$. Also, filter theory also assumes that highly certain events should be able to be processed without delay, a prediction that was not in accord with the present data as it is difficult to conceptualize a more certain situation than the WS condition in Experiment 2.

In its broad form, however, the filter seems one likely locus for the TE delay as it is postulated to prevent disparate sources of stimulation from interacting in later stages of processing. $S_{2}$, if not temporarily gated, would interfere with the processing of $S_{1}$. Two other possible loci have been identified which seem relevant for the TE and other delays. These are a perceptual channel, responsible for perceiving an input by matching it with a mnemonic representation from the set of possible stimuli, and a response system which would translate the processed input and/or matched mnemonic representation into an appropriate output or response command. Although single channel theorists often treat the central processing system as a single unit, research conducted by Bernstein, Schurman, and Forester (1967) and Hohle (1967) suggests at least a two-stage interpretation. Bernstein et al (1967) have shown that as the mapping ratio of stimuli to responses is varied along with the size of the stimulus set, RT varies linearly with the number of stimuli for a fixed number of responses, but as a step function with the number of responses for a fixed number of stimuli. These different functions were interperted as supporting the existence of different mechanisms for recognition and response selection.

Hohle's (1967) method, which involves a statistical analysis of RT distributions into inferred components, has likewise supported the hypothesis that at least two separate phases are present in processing an RT signal. Of interest to the present discussion is that the duration of the assumed perceptual phase is approximately 30-50 msec. This time interval corresponds fairly well to the ISI evoking maximum delay in $\mathbf{R T}_{2}$.

In addition to single channel limitations that may be present at filter and perceptual stages, it is also possible that similar limitations may exist on the response side in deciding to execute a response. It should be noted that this form of response interpretation is not the same as the reponse conflict mechanism described by Reynolds $(1964,1966)$. Although there were some slight changes in the magnitude of the TE delay, the effect was basically stable with extended practice.

The present study confirms the results of several studies indicating time uncertainty to be a relatively potent variable affecting the PRP. Hence, it seems relatively important to incorporate it within single channel theory since the importance of time uncertainty is what originally gave rise to expectancy models (Elithorn \& Lawrence, 1955). This incorporation can be made in part, if it is assumed that $S^{\prime} s$ event uncertainty is not only a function of the nominal set of stimuli but the null events that occur at ISIs prior to the occurrence of a member of the nominal set. In terms of information theory, stimulus uncertainty needs to be measured in terms of probabilities derived from an event-time manifold and not solely in terms of the nominal event set. Clearly, both the absolute and relative values of ISI alter not only $R_{2}$, as Nickerson (1965) has shown, but $\mathrm{RT}_{1}$ as well.

The broad question raised in modern form by the PRP is the extent to which a human operator can "to two things at once." The present experiments suggest a hypothesis in response to this traditional issue. Although delays in responding appear to be rather ubiquitously present for nearly simultaneous stimuli, the duration of the delay is clearly less than the time required to process the stimulation and, if the response 
is simple enough, the consequent RT. 6 If it is assumed that information processing is organized in stages or levels, as many contemporary perceptual and human performance theorists do, then a qualified affirmative answer is possible. In the general context of filter and single channel theory, the three levels of processing: filtering or detection, processing or recognition, and response selection, seem to be organized such that an event located at one stage may coexist with antecedent or subsequent events at other stages. In particular, the functional advantages of a multi-stage system would be that a distinct processing system would serve as a buffer unit to allow response selection to occur for earlier events or highly redundant events not requiring feedback monitoring.

\section{References}

Adams, J. A. Test of the hypothesis of psychological refractory period. J. exp. Psychol., 1962, 64, 280-287.

Adams, J. A., \& Chambers, R. W. Response to simultaneous stimulation of two sense modalities, J. exp. Psychol., 1962, 63, 198-206.

Bernstein, I. H., Schurman, D. L., \& Forester, G. Choice reaction time as a function of stimulus uncertainty, response uncertainty, and behavioral hypotheses. J. exp. Psychol., 1967, (in press),

Bertelson, P. Central intermittency twenty years later. Quart. $J$. Psychol, 1966, 18, 153-163.

Borger, $\mathbf{R}$. The refractory period and serial choice reactions. Quart. J. exp. Psychol., 1963, 15, 1-12

Broadbent, D. E. Perception and communication. New York: Pergamon Press, 1958.

Creamer, L. R. Event uncertainty, psychological refractory period, and human data processing. J. exp. Psychol., 1963, 66, 187-194.

Davis, R. The limits of the psychological refractory period. Quart. J. exp. Psychol., 1956, 8, 24-38.

Edwards. A. L. Statistical methods for the behavioral sciences. New York: Rinehart, 1954.

Elithom, A., \& Lawrence, C. Central inhibition: some refractory observations. Quart..J. exp. Psychol., 1955, 7, 116-127.

Fehrer, E., \& Raab, D. Reaction time to stimuli masked by metacontrast. J. exp. Psychol., 1962, 143-147.

Gottsdanker, R., Broadbent, L., \& Van Sant, C. Reaction time to single and first signals. J. exp. Psychol, 1963, 66, 163-167.

Gottsdanker, R., \& Way, T. C. Varied and constant intervals in psychological refractioners. J. exp. Psychol., 1966, 72, 792-803.
Hick, W. E. The discontinuous functioning of the human operator in pursuit tasks. Quart, J. exp. Psychol., 1948, 1, 36-51.

Hohle, R. H. Component process latencies in reaction times of children and adults. In L. P. Lysett \& C. C, Spiker (Eds.), Adrancess in child development and behatior. Vol. III. New York: Academic Press, 1967, (in press).

Klemmer, E. T. Time uncertainty in simple reaction time. $J$, exp. Psychol., 1956, 51, 179-184.

Marill, T. The psychological refractory phase. Brit. J. exp. Psychol., 1957, 48, 93-97.

Nickerson, R. S. Response time to the second of two successive symbols as a function of the absolute and relative duration of intersignal interval. Percept. mot. Skills, 1965, 21, 3-10.

Reynolds, D. Effects of double stimulation: temporary inhibition of response. Psychol. Bull., 1964, 62, 333-347.

Reynolds, $D$. Time and event uncertainty in unisensory reaction time. J. crp. Psychol., 1966, 71, 286-293.

Smith, M. C. Theories of the psychological refractory period Psychol. Bull., 1967, 67, 202-213.

Telford, D. W. The refractory phase for voluntary responses, $J$. exp. Psychol., 1931, 14, 1-35.

Welford, A. T. The psychological refractory period and the timing of high speed performance: a review and a theory. Brit. J. exp. Psychol, 1952, 43, 2-19.

\section{Notes}

1. Supported in part by NIMH grant 12530-01, to the senior author. The authors are grateful to Mr. Larry Morris for conducting relevant pilot studies and to Mr. William Gramling and Mrs. Gladys Wenner for their critique. Experiment 1 was reported at the 1967 convention of the Midwestern Psychological Association.

2. Now at Vanderbilt University.

3. Now at the University of Oregon.

4. Reynolds" position has justifiably been considered "single channel" (Smith, 1967) since it attributes response degradation to limited capacity effects. However, it is considered in contrast to the above variations upon Welford's single channel model, since Reynolds is concerned with output rather than input limitations. 5. As comparisons frequently generated $z$ values larger than those listed in standard tables, it was decided to place a lower limit of $\mathrm{p}$ as .0001 even if $\mathrm{z}$ values exceeded this $\mathrm{p}$.

6 . One difficulty, noted previously (Reynolds, 1966) with regard to the interpretation of studies using tracking tasks is that tracking tasks often involve complex responses which involve a relatively large contribution of peripheral factors

(Accepted for publication November 6, 1967.) 